\title{
Quiet-time mid-latitude trough: influence of convection, field-aligned currents and proton precipitation
}

\author{
H. Nilsson ${ }^{1}$, T. I. Sergienko ${ }^{1}$, Y. Ebihara ${ }^{2}$, and M. Yamauchi ${ }^{1}$ \\ ${ }^{1}$ Swedish Institute of Space Physics, Kiruna, Sweden \\ ${ }^{2}$ National Institute of Polar Research, Tokyo, Japan
}

Received: 5 November 2004 - Revised: 2 September 2005 - Accepted: 9 September 2005 - Published: 30 November 2005

\begin{abstract}
A combination of EISCAT CP-3 (latitude scans) and satellite (DMSP) data have been used to study the structure of the quiet-time evening-sector auroral and subauroral ionosphere, in particular the mid-latitude trough. The main mechanism behind trough formation in the quiet-time evening sector ionosphere is believed to be flow stagnation in a region where convection and corotation counteract each other. However, there is also the possibility that field-aligned currents (FAC) more directly modify the ionospheric density if the current is carried by thermal ionospheric electrons. A quantitative test of the flow-stagnation scenario and an estimate of the possible direct effects caused by field-aligned currents have been performed. We found that the electron densities observed can indeed be explained by the flowstagnation scenario, but the electron density altitude profiles in the trough sometimes differ from what should be expected from flow stagnation. The effect of a downward field-aligned current cannot be identified in the data, but a simple estimate shows that it can affect the ionospheric plasma density, causing decreased ionospheric densities. In the quiet-time region 2 current/trough region there is typically a significant ion production resulting from proton precipitation which may counteract this effect. Charge exchange of the precipitating protons causes a lateral spread and a smooth associated conductance enhancement. Thus, whereas the proton number flux is insufficient to directly carry the evening sector region 2 current, the precipitation in practice produces the necessary charge carriers. We suggest that precipitating protons do play a crucial role in the electrodynamics of the dark evening sector ionosphere by causing a small but smooth conductance enhancement and producing the charge carriers necessary to carry the trough-associated downward field-aligned current.
\end{abstract}

Keywords. Ionosphere (Auroral ionosphere; Electric fields and currents) - Magnetospheric physics (Magnetosphereionosphere interactions)

Correspondence to: H. Nilsson

(hans.nilsson@irf.se)

\section{Introduction}

The purpose of this paper is to report studies of the closelyrelated phenomena of proton precipitation, the region 2 fieldaligned current (R2 FAC) region and the formation of the mid-latitude trough in the quiet-time evening sector ionosphere. Our interest lies in the conductance of the ionosphere and the availability of charge carriers. The latter may be important both for the magnetosphere charge carrier budget, in general, but possibly also for auroral acceleration events that presumably take place later during more disturbed times (e.g. see discussion on role of ionospheric conductance in Newell et al., 1996). In particular, we can expect the trough to be very effectively "pre-processed" for strong auroral acceleration events due to the very low densities expected and because it occurs on the border between magnetospheric regions. Low densities can occur through both stagnation and decay due to long residence time in darkness (e.g. Knudsen, 1974), ionospheric cavity formation due to a downward field-aligned current (e.g. Lyatsky and Mal'tsev, 1981), ionospheric outflow due to a pressure gradient along the field line, as well as enhanced losses due to strong electric fields (Schunk et al., 1975). The effect of downward field-aligned currents is particularly interesting as this constitutes a lowconducting counterpart to the ordinary aurora associated with upward field-aligned currents and may give rise to considerable ionospheric and auroral structure.

Most studies of the quiet-time evening sector mid-latitude trough indicate that it can be explained by plasma stagnation in a region where corotation and convection electric fields counteract each other, leading to a long residence time in darkness and therefore decay due to recombination (e.g. Spiro et al., 1978; Brinton et al., 1978; Senior et al., 1987; Robinson et al., 1982; Collis and Häggström, 1988; Hedin et al., 2000). In the evening sector ionosphere this plasma stagnation occurs on the border between the corotation and the shielding electric field associated with the R2 FAC (e.g. Blanc and Caudal, 1985, see below). On average, the convection caused by the shielding electric field is westward and the 
corotation is eastward and at some point these two influences cancel each other out causing flow stagnation. Ionospheric plasma further into the westward flow region, poleward of the flow stagnation region, is expected to come from the polar cap and shows higher densities, constituting the poleward "wall" of the trough. This is caused in part by local $F$-region production, due to electron precipitation (Jones et al., 1997). None of the above-mentioned detailed incoherent scatter (IS) radar studies of the evening sector trough have attempted a quantitative test of the flow stagnation theory, nor investigated the possible direct influence due to a downward fieldaligned current. This is attempted in this paper. IS radar measurements also allow us to determine if strong electric fields affect the ionospheric plasma during the measurements (Rodger et al., 1992). Crickmore et al. (1996) attempted to model the expected effect on the altitude distribution of $F$ region plasma due to different formation processes, to allow for the identification of the trough formation process even after the active formation (in the case of strong electric fields). We will complement this study by showing trough altitude profiles of $F$-region electron density. We note that for higher disturbance levels the trough and shielding electric field is observed at lower latitudes, and the mid-latitude incoherent radar at Millstone Hill has been used in very extensive studies of the associated disturbed time phenomena (Foster and Vo, 2002). At such disturbed times the trough and enhanced electric field (termed the Sub Auroral Polarization Stream) becomes detached from the auroral oval, and appears as a second electric field peak several degrees equatorward of the main auroral oval.

The electric field associated with the R2 FAC is caused by the separation of electrons and ions due to the chargedependent gradient drift, which also gives rise to the ring current (e.g. Blanc and Caudal, 1985; Senior and Blanc, 1984). In the evening sector ionosphere the gradient-B and curvature drift causes the ions to reach lower latitudes than the electrons, creating a northward-directed electric field. This northward electric field shields the lower latitude magnetosphere from the imposed high-latitude magnetospheric electric fields. Current continuity in the ionosphere shows that the associated field-aligned current is downward. If the protons giving rise to the electric field are precipitating, then proton precipitation may extend further equatorward than electron precipitation. This is a well-known statistical result from satellite observations of the evening sector ionosphere (Hardy et al., 1989), as well as from observations of electron and proton aurora (e.g. Fukunishi, 1975; Galand et al., 2002). A satellite study reported by Fujii et al. (1990) has shown that the equatorward border of the proton precipitation is closely co-located with the equatorward border of the region 2 field-aligned current (R2 FAC), for all levels of geomagnetic activity. The latter distinguishes the proton precipitation border from the electron precipitation border, which has a more variable position relative to the R2 FAC border. A conclusion of these observations is that proton precipitation is likely to occur close to or within the quiet-time trough region.
One should note here that the number flux of precipitating protons is generally too low to directly carry a significant part of the R2 FAC, which one would instead expect to be carried by thermal electrons (Yamauchi et al., 1998). In the downward current region the ionosphere must supply thermal electrons to carry the current. It has long been recognized that the ionospheric plasma density may be affected by the field-aligned current in such a situation (both $F$-region, e.g. Block and Fälthammar, 1968, and $E$-region, e.g. Banks and Yasuhara, 1978). More recently, Doe et al. (1995); Karlsson and Marklund (1998) have carried out simulations indicating that field-aligned currents can be very effective in creating $F$-region density cavities. Therefore, the R2 FAC could possibly play a direct role in the formation of the mid-latitude trough, as is indeed suggested by Lyatsky and Mal'tsev (1981), a possibility which has been overlooked in previous studies and which we discuss in Sect. 4.2. The recent simulations were valid for relatively narrow structures, but if the ionosphere "runs out" of charge carriers the structure of the $F$-region trough is likely to be affected. Because the $F$-region plasma is long-lived, it is very difficult to prove observationally that a density depletion was created by a specific mechanism, as this mechanism may not be at work at the time of observation. This is a further reason to use quiet and stable times to look for field-aligned current effects on $F$ region plasma density, even though the effects may be less dramatic for such conditions.

We have used data from the most quiet days, available from the EISCAT Common Program 3 (latitudinal scans), complemented with DMSP satellite data. We established the detailed observational signature of the $E$ - and $F$-regions in the trough based on a case study of one of these days, 25 October 1988. For the $F$-region structure we determined the total densities and used them as an estimate of the degree of depletion in the trough. We investigated altitude profiles, as these may provide clues to the mechanism in operation. The observational results of the case study were compared with an empirical model of ionospheric decay caused by long residence time in darkness, made using the equatormost part of the observations. Based on this result we investigated whether any further loss mechanisms were needed to explain the data and quantified the possible influence of a downward field-aligned current. We also compared the latter with observed local production, to estimate the charge carrier budget, and thus further examine if the downward field-aligned current may influence the ionospheric density structure. We paid particular attention to the ionization in the trough produced by proton precipitation.

\section{Observational techniques}

\subsection{Incoherent scatter radar observations}

The ESICAT tristatic UHF radar operates at $933 \mathrm{MHz}$, with a transmitter and receiver in Troms $\varnothing$, Norway $\left(69.6^{\circ} \mathrm{N}\right.$ 19.2 $\left.{ }^{\circ} \mathrm{E}\right)$, and receivers in Kiruna, Sweden $\left(67.9^{\circ} \mathrm{N}, 20.4^{\circ} \mathrm{E}\right)$ 
and Sodankylä, Finland $\left(67.4^{\circ} \mathrm{N}, 26.6^{\circ} \mathrm{E}\right.$ ), (see Folkestad et al. (1983) for a technical description). The tristatic observations allow for unambiguous determination of the flow in one volume along the transmitter radar line of sight. Using the Troms $\varnothing$ transmitter and receiver site, altitude profiles of electron density, electron temperature, ion temperature and ion line-of-sight velocity can be obtained from the standard ion-line analysis (ACF data). This is complemented with power profiles (estimates of electron density) with higher spatial resolution.

For this study the database of the EISCAT UHF incoherent scatter radar, operating in the Common Program 3 mode (CP3), was used. CP3 consists of latitude scans in the magnetic meridian plane. Only version CP3-E and later versions have been used (i.e. data from 1986 and onward). The scan consists of 17 positions, of which 16 are in the meridian plane through Troms $\varnothing$ and Kiruna. The first position in every scan is directed $20^{\circ}$ to the east of the magnetic meridian and may be used to estimate field-perpendicular flows in the northernmost part of the observed area, using the "beamswing technique". The CP3 mode of operation is described in more detail in Collis and Häggström (1988) and in Turunen (1986). The range resolution of the ACF data varies during the scan and between different versions of CP3 but is in the range $42-54 \mathrm{~km}$ for $\mathrm{CP} 3$ version $\mathrm{F}$, sampled at a range interval of $31.5 \mathrm{~km}$. The power profiles have a range resolution of $10.5-14.7 \mathrm{~km}$ in the altitude interval of approximately 60 to $450 \mathrm{~km}$ sampled at $2.1 \mathrm{~km}$ intervals. Tristatic measurements are made at $275 \mathrm{~km}$, allowing for the determination of ionospheric convection, as well as field-aligned flows (though the latter is very sensitive to the assumed magnetic-field direction).

\subsection{Satellite observations}

The satellite data used for this study come from the Defense Meteorological Satellite Program (DMSP) series of satellites, using the SSJ/4 detector and SSIES detector. The DMSP F6-F9 satellites are in circular, $840 \mathrm{~km}$, Sunsynchronous orbits at an inclination of $98.3^{\circ}$. The reader is referred to Hardy et al. (1989) and references therein for details on the SSJ/4 detector and its capabilities. Here it suffices to note that precipitating ions and electrons are measured in the energy range $30 \mathrm{eV}-\sim 1 \mathrm{keV}$ and $\sim 1 \mathrm{keV}-30 \mathrm{keV}$ in the low- and high-energy range detectors, respectively. Each detector has 10 channels, spaced at equal intervals in energy on a logarithmic scale. Furthermore, the SSIES detector (Rich, 1994) on board the DMSP F8 satellite has been used for estimates of electron density and ion drift. The ion drift is measured perpendicular to the satellite orbit, which may be an important limitation.

\section{Observations}

Initially, days with $K_{p}$ values of 2 and less were picked out for further study, chosen from the EISCAT CP3 database
Table 1. Dates of ESICAT CP3 runs chosen for this study. The average $K_{p}$ is the average of the available measurement points during trough observation.

\begin{tabular}{lcc}
\hline Date & Average $K_{p}$ & $\mathrm{~F} 10.7 \mathrm{~cm}$ index \\
\hline 1 April 1986 & 2.0 & 71.8 \\
2 April 1986 & 1.2 & \\
3 April 1986 & 2.7 & \\
4 April 1986 & 1.8 & 69.3 \\
27 August 1986 & 2.2 & 69.1 \\
28 August 1986 & 3.5 & 68.8 \\
23 September 1986 & 5.0 & 68.7 \\
24 September 1986 & 3.0 & 68.8 \\
25 September 1986 & 3.5 & 69.4 \\
7 October 1986 & 1.1 & 74.3 \\
8 October 1986 & 2.7 & \\
31 March 1987 & 0.83 & 71.9 \\
28 April 1987 & 0.14 & 74.3 \\
29 April 1987 & 1.5 & \\
19 May 1987 & 0.71 & 100.1 \\
20 May 1987 & 0.87 & \\
25 October 1988 & 0.7 & 162.1 \\
26 October 1988 & 2.1 & \\
9 May 1989 & 1.5 & 205.1 \\
10 May 1989 & 0.7 & \\
\hline
\end{tabular}

for the time period between 1986 and 1998. For multi-day runs the days with $K_{p}$ larger than 2 were used if the trough was within the EISCAT CP3 field-of-view. Data from 1986 was checked even for higher activity levels because a lot of good data existed from the Viking coordinated campaigns (e.g. Opgenoorth et al., 1989). Normally, the trough moves equatorward and is outside the field-of-view of EISCAT CP3 for high activity levels. This is consistent with the Millstone Hill results of Foster and Vo (2002), who found that $K_{p}$ had to be above 2 for the trough to be within the Millstone Hill radar field-of-view, which basically complements the EISCAT radar field-of-view in magnetic latitude. The days investigated are listed in Table 1. EISCAT CP3 runs until 1998 were checked for low $K_{p}$ levels but no suitable days were found after 1989.

We present a detailed case study based on 25 October 1988 , complemented with some results from case studies of 26 October 1988 and 7 October 1986. In particular, 25 October 1988 represents a day when the ionospheric electric fields was relatively stable. Figure 1 shows the peak $E$-region electron density in the $90-160 \mathrm{~km}$ region, and Fig. 2 shows the peak $F$-region density in the $300-500 \mathrm{~km}$ region for this day. Both are plotted using corrected geomagnetic latitude of the magnetic footpoint at $100 \mathrm{~km}$ altitude and magnetic local time. Each data point has been plotted at the time/position it was recorded but with a width which is larger than the actual acquisition time to improve readability. Superimposed are arrows indicating the horizontal convection estimated from the tristatic radar measurements at $275 \mathrm{~km}$ altitude, with the 


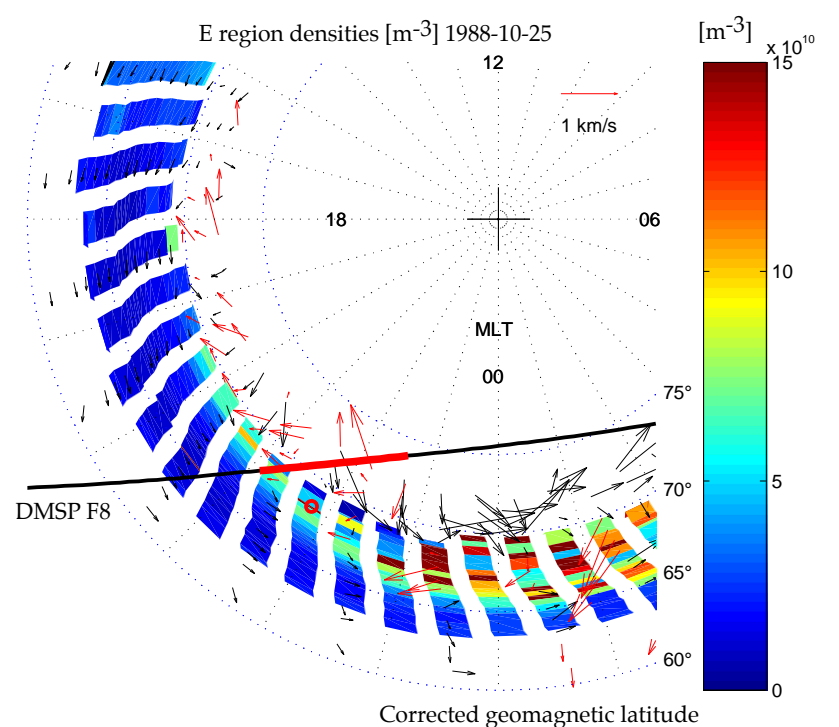

Fig. 1. Overview plot of $E$-region electron density $\left[\mathrm{m}^{-3}\right]$ on 25 October 1988 using corrected geomagnetic latitude of the magnetic footpoint at $100 \mathrm{~km}$ and magnetic local time. The $E$-region data displays the maximum electron density in the $90-160 \mathrm{~km}$ altitude region. Superimposed are convection estimates with the arrow length corresponding to the velocity as $250 \mathrm{~m} / \mathrm{s}$ per degree latitude length. The black line shows the track of the DMSP F8 satellite mapped along the field line to $100-\mathrm{km}$ altitude. The thick red line shows the region where the satellite observed proton precipitation. The thick red circle shows the $100-\mathrm{km}$ footpoint of the point where the radar was making $E$-region observations at the time corresponding to the red line along the satellite track.

corotation added. Adding a corotation electric field allows for an estimate of the flow lines in a reference frame fixed relative to the Sun. This is particularly important for trough studies, and for studies of the convective time history of a magnetospheric field line.

Figure 1 depicts a rather typical quiet-time ionosphere, with the diffuse aurora coming from poleward into the EISCAT CP3 field-of-view in the evening sector, from around 18 MLT, reaching its lowest latitude at or after magnetic midnight and then retreating poleward again. By diffuse aurora we mean the unstructured density enhancements in the $E$ region. The diffuse precipitation and the trough, which is clearly seen as a region of low density in Fig. 2, are closely co-located (show a similar latitude vs. MLT variation) at least until 22 MLT. The diffuse aurora is mainly observed in the westward flow region, though it does extend into the corotating region. As discussed in the Introduction, it is likely that the equatormost part of the diffuse precipitation is made up of proton precipitation. Precipitating protons undergo significant charge exchange in the ionosphere, resulting in a spread of the distribution across field lines. Thus, the observed density enhancements do not necessarily mean that precipitation occurs in the corotation region. To determine precisely where protons precipitate it is necessary to use satellite observations. Figures 1 and 2 show the track of

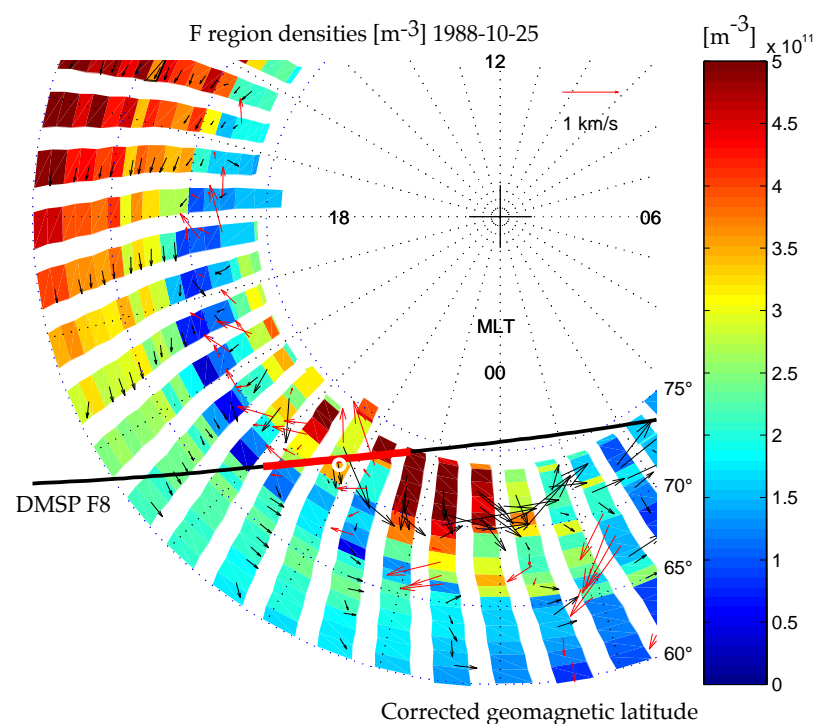

Fig. 2. Overview plot of $F$-region electron density $\left[\mathrm{m}^{-3}\right]$ on 25 October 1988 using corrected geomagnetic latitude of the magnetic footpoint at $100 \mathrm{~km}$ and magnetic local time. The $F$-region data displays the maximum electron density in the $300-500 \mathrm{~km}$ altitude interval. Superimposed are convection estimates with the arrow length corresponding to the velocity as $250 \mathrm{~m} / \mathrm{s}$ per degree latitude length. The black line shows the track of the DMSP F8 satellite mapped along the field line to $100-\mathrm{km}$ altitude. The thick red line shows the region where the satellite observed proton precipitation. The thick white circle shows the $100 \mathrm{~km}$ footpoint of the point where the radar was making $F$-region observations at the time corresponding to a red line along the satellite track.

the DMSP F8 satellite (between 19:36-19:42 UT) mapped along the field line to $100 \mathrm{~km}$ altitude as a black line. They show the region where the satellite observed proton precipitation with a thick red line. In Fig. 1 a thick red circle depicts the $100-\mathrm{km}$ footpoint of the position, where the radar was making observations at the time, corresponding to the red line along the satellite track. A thick white circle depicts the same thing in Fig. 2.

Figure 3 shows the observations corresponding to the closest conjunction between the DMSP F8 satellite and the EISCAT observations.

Panel (a) shows the DMSP data. A green line depicts electron density at $840 \mathrm{~km}$. A clear trough centered on $68.5^{\circ}$ (corrected geomagnetic latitude of magnetic footpoint at $100 \mathrm{~km}$ altitude) can be seen. Inside this trough significant proton precipitation occurs, shown by the proton energy flux reaching somewhat above $10^{11} \mathrm{eV} \mathrm{cm}^{-2} \mathrm{~s}^{-1}$ (black line). The average proton energy was in the range $13 \mathrm{keV}$ in the equatormost part and fell gradually to $4 \mathrm{keV}$ in the poleward part of the region with significant proton energy flux. A blue line shows the electron energy flux, and the data confirms that the proton precipitation occurs further equatorward than the electron precipitation. The average electron energy was $1.5 \mathrm{keV}$ during the time of significant energy flux. Panel (b) of Fig. 3 shows the corresponding EISCAT data. A green 
line depicts the $F$-region electron density at $275 \mathrm{~km}$, and a clear trough can be identified at the same latitude as in the DMSP data, but extending further equatorward. A blue line depicts the ionospheric Pedersen conductance. The Pedersen conductance was calculated by interpolating the scan data on a $0.2^{\circ}$ by $2 \mathrm{~km}$ grid and by using the MSIS 90 model atmosphere (Hedin, 1991) and by assuming equal electron, ion and neutral temperatures. For further details on calculating the ionospheric conductance from ISR data, see Senior (1991) and references therein. The poleward side of the trough coincides with electron precipitation in both the DMSP and EISCAT data, in the latter case seen as steeply increasing and more structured conductance. The east-west ion drift at 275-km altitude, measured using tristatic EISCAT estimates, has been recalculated to a corresponding northward electric field and is shown with a red line. The plot shows a gradual transition from very low electric fields equatorward of the trough to significant fields of about $25 \mathrm{mVm}^{-1}$ in the poleward part of the trough. The electric field shows a spatial positive correlation with conductance, increasing as the conductance increases. This is the opposite of what can be observed in smaller scale features where the electric field and conductance are often anti-correlated due to polarization effects (i.e. charges built up on the border of conductance structures, acting to keep the horizontal current constant). Finally, panel (b) shows an estimate of the field-aligned current (FAC) based on the continuity of the observed poleward Pedersen current, which is assumed to close through fieldaligned currents. We have calculated the total current that must flow into the ionosphere between the available EISCAT measurement points to keep the current continuity. The plot assumes that the FAC is evenly distributed between these measurement points (cyan line). The conductance used to calculate the Pedersen current has been slightly extrapolated at the ends of the measurement interval, using the end values also somewhat equatorward and poleward of the actual measurements. Thus, two more electric field values could be taken into account (electric fields are estimated at $275-\mathrm{km}$ altitude so that the latitude sampling is different from the $E$ region measurements). The FAC estimates range from close to zero in the equatorward part to $0.7 \mu \mathrm{A} \mathrm{m}^{-2}$ in the polemost part. If there is any fine structure, then part of it will have denser currents. Finally, panel (c) of Fig. 3 shows the ionization production rate calculated from the EISCAT $E$ region density measurements; see Sect. 4.2 for further discussion.

The conductance observed in the vicinity of the trough deserves some particular attention. The ionospheric Pedersen conductance resulting from the precipitation observed by DMSP has been calculated using the method described by Rees (1989) for electron precipitation and the method described by Galand and Richmond (2001) for proton precipitation. The method of Galand and Richmond (2001) is a simplified parameterization of the Pedersen conductance resulting from proton precipitation based on the proton energy flux. For this work it is enough because we are mainly interested in the difference in latitudinal distribution of the con-

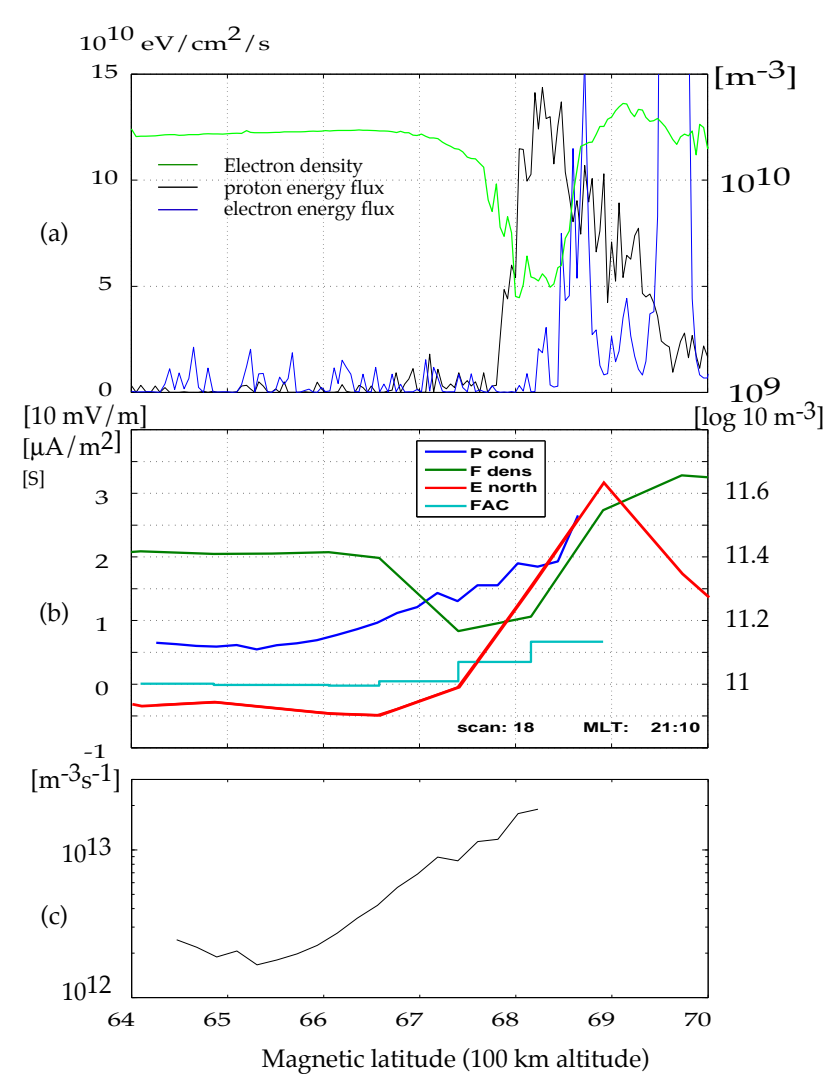

Fig. 3. Latitude profiles of trough parameters from 25 October 1988. (a) Electron density (green line, $\mathrm{m}^{-3}$ ), proton energy flux (black line, $10^{10} \mathrm{eV} \mathrm{cm}^{-2} \mathrm{~s}^{-1}$ ) and electron energy flux (blue line, $10^{10} \mathrm{eV} \mathrm{cm}^{-2} \mathrm{~s}^{-1}$ ), as measured by the DMSP F8 satellite between 19:38 and 19:41 UT, at an altitude of $840 \mathrm{~km}$. (b) EISCAT estimates of electron density at $275 \mathrm{~km}$ altitude (green line, log 10 $\mathrm{m}^{-3}$ ), electric field derived from tristatic plasma velocity measurements at $275 \mathrm{~km}$ altitude (red line, $10 \mathrm{mV} \mathrm{m}^{-1}$ ), ionospheric Pedersen conductance estimated from EISCAT data (blue line, S) and field-aligned current inferred from the electric field and conductance estimates (cyan line, $\mu \mathrm{A} \mathrm{m}^{-2}$ ). (c) The ionization production rate is derived from EISCAT measurements of $E$-region density enhancements, assuming a steady state. $\left(\mathrm{m}^{-3} \mathrm{~s}^{-1}\right)$.

ductance when calculated from DMSP data (and not describing the lateral spread) and as observed by EISCAT. Furthermore, it is likely that a future statistical study on conductance in the trough using satellite data would use such a simplified parameterization. Examples for two different days, 7 October 1986 and 25 October 1988, are shown in Fig. 4. For the case of 25 October 1988, DMSP data is compared with EISCAT data taken from the scan closest in magnetic local time, not the time of observation (the scan before closest conjunction in Fig. 1), i.e. the structures are assumed to be stationary. The similarity is very good except for the equatorward slope.

The precipitation observed by DMSP exhibits a sharp equatorward cutoff, whereas the EISCAT measured enhanced electron density falls off gradually towards lower latitudes. This is due to charge exchange (e.g. Davidson, 1965; Kozelov, 1993). Such a gradual slope is observed in the 


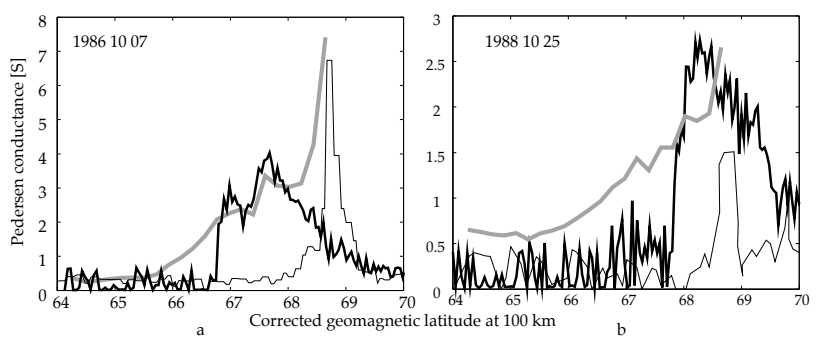

Fig. 4. Conductances $[S]$ calculated using power profile data from the $90-200 \mathrm{~km}$ altitude region (broad grey line), DMSP proton (thick black line) and DMSP electron data (thin black line) on (a) 7 October 1986 (DMSP data from 19:06-19:09 UT, EISCAT data from 19:00-19:30 UT) and (b) 25 October 1988 (DMSP data from 19:38-19:41 UT, EISCAT data from 19:00-19:30 UT). No charge exchange spreading was included in the calculation of the conductance expected from the proton precipitation.

EISCAT data throughout the quiet-time evening of 7 October 1986 and 25 October 1988. This is important because it provides a conductance enhancement with a gradient in the right sense to sustain a downward FAC in the equatorward part of the westward flow region. For this paper it suffices to note that the smooth equatorward border of the diffuse ionization zone typically observed with EISCAT (though we show only one sample scan from each case in Fig. 4) is consistent with the more abrupt equatorward cutoff of proton precipitation, as typically observed by DMSP. Finally, the DMSP data confirm that the conductance enhancement at the poleward edge of the trough is caused by electron precipitation.

\section{Formation of the trough}

\subsection{The flow-stagnation scenario}

In order to make a quantitative estimate of trough formation due to flow stagnation and decay, one needs to describe the flow and the decay. The former can be estimated by setting up a suitable, time-independent electrostatic electric field and calculating the corresponding potential lines (equivalent to flow lines). For the latter an empirical estimate can be used, based on the lowest latitude measurements, which represents unperturbed co-rotating plasma, decaying due to long residence time in darkness.

In our model, the model electric field leading to the flow is described by an imposed (uniform) magnetospheric electric field $E_{m s p}$, the latitude down to which this field is unshielded (constant) $\theta_{\text {unshield }}$ and the latitude below which this field is completely shielded $\theta_{\text {shield }}$, i.e. below this latitude the plasma is co rotating. In the region in between, the electric field varies linearly between the two boundary values, and this is the region where the flow stagnation occurs. Observations show that the imposed electric field is mapped to lower latitudes at later MLT, for example, Fig. 2, as well as in the studies of Senior et al. (1987); Robinson et al. (1982); Collis and Häggström (1988); Hedin et al. (2000), so this behavior must be incorporated in the model. A linear expansion rate $R_{M L T}$ describes the more equatorward position of the westward flow for later MLT, (i.e. $\theta_{\text {unshield }}=\theta_{\text {unshield } 0}-R_{M L T} \times \Delta \mathrm{MLT}$ and similarly $\theta_{\text {shield }}=\theta_{\text {shield } 0}-R_{M L T} \times \Delta \mathrm{MLT}$ where index 0 indicates the intial value and $\triangle$ MLT is the time from the starting point of the calculation). Finally, the calculation is stopped at some time close to magnetic midnight, and the flow lines coming from the east side represent field lines convected over the polar cap. The potential distribution which also describes the flow lines of the plasma (shown in Fig. 5, panel (b)), can then be calculated from the described electric field. The time it takes to reach each point along each flow line is then calculated. The resulting densities can then be calculated if an estimate of the decay of the $F$-region plasma, due to a certain residence time in darkness, can be made. The EISCAT measurements of unperturbed corotating plasma in the equatorward part of the scan can be used to obtain an empirical plasma density vs. time function, as is justified below.

For the quiet conditions studied on 25 October 1988 (Figs. 2 and 5a,c) the plasma in the most equatorward part of the scan is corotating and decaying smoothly. It can thus be assumed that this is an unperturbed plasma decaying due to the residence time in darkness. The trough field lines are observed at somewhat higher latitudes than the corotating reference plasma, which may be a problem. As the latitude changes the main nightside ionization sources in the absence of precipitation, scattered light and starlight, are uniform in space and time (Schunk and Nagy, 2000). The same is true for recombination, which should have no particular latitude dependence. The main uncertainty is transport differences. If we assume that the protonosphere plasma is cold enough to be tied to the field line, the high altitude plasma moves with the low altitude plasma, so the only change is the field line length/flux-tube volume. High latitude field lines are longer and this may limit the down-flow/increased upflow compared to low-latitude field lines. Figure $5 \mathrm{c}$ confirms in a line plot that there is no latitudinal dependence of the smooth decay of the corotating plasma. The equator-most values can therefore be used to interpolate plasma density after a given time in darkness, i.e. the model densities start with the plasma densities observed in the equatormost part of the observations and decay at the same time rate.

To take into account the possibility that the shape of the electron density altitude profile is not preserved (see Sect. 4.3), it is desirable to use the "entire $F$-region electron content" as electron density variable. In practice, the altitude range $250 \mathrm{~km}$ to $500 \mathrm{~km}$, covering most of the peak $F$-region densities, turns out to be feasible for our data set. The choice of altitude range is a trade-off between truly capturing all of the $F$-region plasma (see Sect. 4.3) and covering as large a latitude interval as possible using the radar scan (far from the radar the lowest altitudes are not observed, and the highest altitudes may be difficult to observe due to the long range). In practice the choice of lowest altitude of $250 \mathrm{~km}$ leads to an underestimation of the real "entire $F$-region content" for the case of 25 October 1988 of up to $10 \%$. 

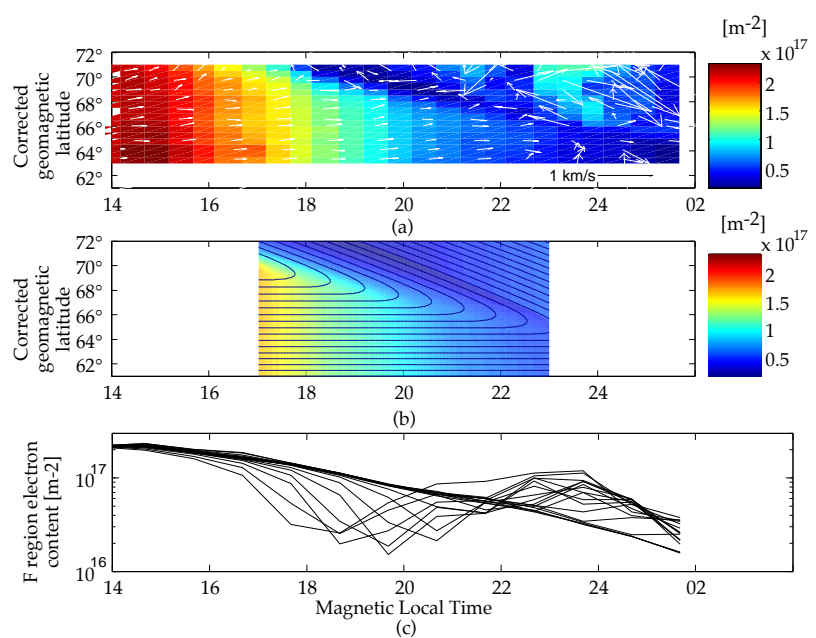

Fig. 5. $F$-region electron $\left[\mathrm{m}^{-2}\right]$ content between 250 and $500 \mathrm{~km}$ altitude in the trough region (a) as observed on 25 October 1988 (latitude range $63^{\circ}$ to $71^{\circ}$ ) and (b) as calculated from a simple "flow stagnation" model. A corotation electric field has been added to show flow in an inertial reference frame. The imposed magnetospheric electric field in the model polar cap is $20 \mathrm{mV} / \mathrm{m}$. Plate (c) shows the observations as line plots instead, one line for every degree latitude covered by the measurements.

Finally, it is convenient to represent the initial "polar cap" with values determined from the equator-most plasma densities which were used to estimate the decay rate, but with an offset variable $t_{\text {pcap }}$. This can be compared with the oftencited calculation by Spiro et al. (1978), where the values representing the poleward wall were set to an arbitrary constant value. The result of such a calculation is shown in Fig. 5, panel $b$, together with the data from 25 October 1988 shown in the same format (panel (a)).

With the chosen parameters $\theta_{\text {unshield }}=71^{\circ}, \theta_{\text {shield }}=69^{\circ}$, $R_{M L T}=0.025^{\circ}$ per calculation time step of $0.03 \mathrm{~h}$, $E_{m s p}=20 \mathrm{mVm}^{-1}$ and $t_{\text {pcap }}=4 \mathrm{~h}$ the agreement is rather good. Note, however, how variable the observed magnitude of the polar cap electric field is. Still, this variability does not substantially affect the morphology of the trough. Panel (c) of Fig. 5 depicts the change in the " $F$-region plasma content" with time as a line for each degree of latitude. As can be seen, the decay is smooth and the low-latitude lines are indistinguishable from each other, indicating a very small latitude dependence of the decay. The lines showing rapidly falling densities correspond to higher latitudes. The low densities correspond to direct observations of the trough.

Figure $6 \mathrm{~b}$ depicts the calculated trough " $F$-region plasma content" latitude profiles, showing a rather constant minimum, just as for the real measurements in Fig. 6a. There is more variability in the measurements, but this corresponds to more variable electric fields, yielding a somewhat varying residence time in darkness, as well as likely a more variable position of the poleward wall ( $\theta_{\text {unshield }}$ in the model). Increasing the imposed polar cap electric field in the model to the still reasonable value $50 \mathrm{mVm}^{-1}$ yields a lower decrease in
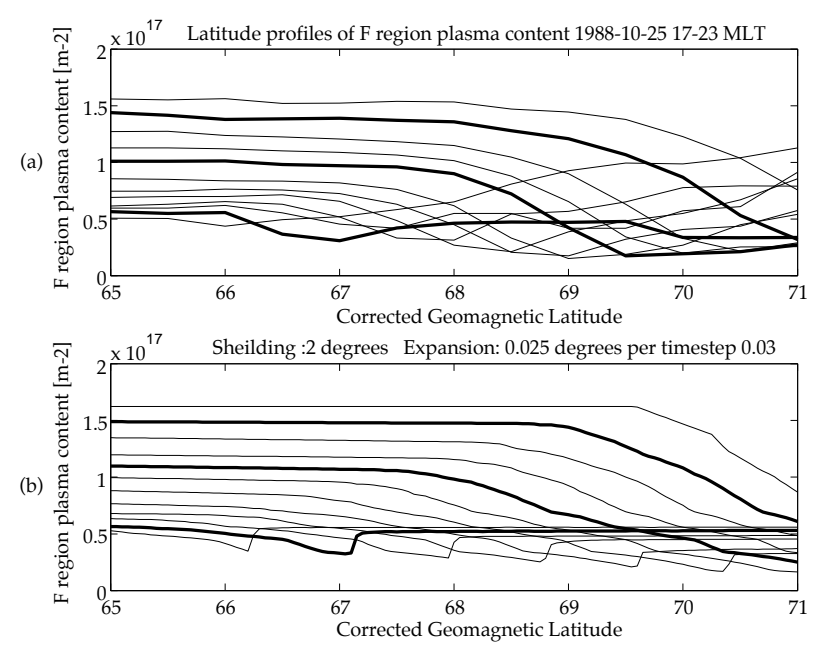

Fig. 6. Latitude profile of $F$-region electron content between 250$500 \mathrm{~km}$ altitude $\left[\mathrm{m}^{-2}\right]$ as observed on 25 October 1988 (a) and based on a calculation of expected densities due to flow stagnation (b). Each line represents different times, each half- hour between 17 and 23 MLT. High density in the equatorward part and high latitude of the trough represents early times. Three representative latitude contours are shown with bold lines to enhance readability.

the trough minimum towards early MLT. The closer the balance between the imposed electric field and the corotation electric field, the more the trough minima will deepen towards early local time because of long transport times. For high imposed electric fields the opposite is true, trough minima will be fairly constant. However, high electric fields may cause additional plasma depletions, (e.g. see discussion in Rodger et al., 1992). The evolution of the equatorward slope with MLT, which is a signature of the flow stagnation scenario, agrees very well between model and observations. A stagnation trough must, by definition have a rather weak equatorward structure at one of the last field lines turning from corotation to westward flow. This is also found in the data (Fig. 6 a).

A further comparison between the calculated minimum $F$ region electron content with the observed one is shown in Fig. 7. Note that the increasing values for early MLT are because the trough minimum is not within the radar/simulation field-of-view. As can be seen, the agreement is very good. The agreement is better than in Fig. 6 because latitudinal differences where the trough minima are observed are not taken into account. This is anyway a relevant comparison because, due to a variable position of the region with a significantly imposed magnetospheric electric field, the morphology of the trough can be expected to change somewhat. Figure 7 then shows that there are flow lines where the resulting decay is just the same as observed, even though the precise geographical position is not the same as in the model. The rather good similarity seems to leave very little room for any additional effects other than the flow stagnation and decay. 


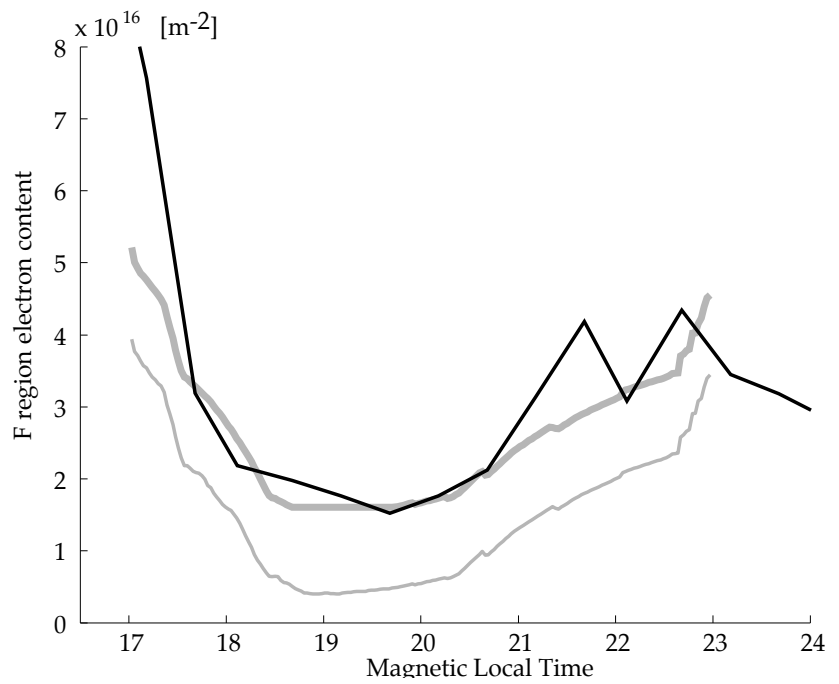

Fig. 7. Comparison of calculated trough electron content $\left[\mathrm{m}^{-2}\right]$ in the 250 to $500 \mathrm{~km}$ region (thick grey line), with those observed on 25 October 1988 (thick black line). The thin grey line shows the calculation result when an electron outflow loss corresponding to a $1 \mu \mathrm{Am}^{-2}$ field-aligned current is included.

\subsection{Effect of field-aligned currents}

As mentioned in the Introduction, there has been some work on the possibility that field-aligned currents directly influence the $E$ - and $F$-region ionospheric plasma (Block and Fälthammar, 1968; Banks and Yasuhara, 1978; Doe et al., 1995; Karlsson and Marklund, 1998). In the evening sector ionosphere this mechanism would be particularly interesting as the R2 FAC could then contribute directly to the trough formation process.

Throughout the altitude region of interest $(90 \mathrm{~km}$ and upward) electrons are $\boldsymbol{E} \times \boldsymbol{B}$ drifting, so, to a first approximation, there is no horizontal electron transport in the moving field line reference frame. Any current into the ionosphere will remove the amount of electrons needed to carry the current (assuming the current is carried by thermal ionospheric electrons and closed through Pedersen currents carried by $E$ region ions). The ionospheric loss rate due to a field-aligned current can then be estimated by the number of electrons flowing out at a given current density. In the dark ionosphere the $E$-region ionosphere may quickly be depleted and there is thus a possibility that the $F$-region is affected, as in the modeling work of Doe et al. (1995); Karlsson and Marklund (1998). The largest possible effect is that the $F$-region is depleted at the rate indicated by the field-aligned current loss rate. The mobile electrons can easily flow from the $F$ region to the magnetospheric source; the limiting factor is the flow of the $F$-region ions and the effect on the current of the very low $E$-region conductance. As pointed out by Doe et al. (1995), the conductance gradients of an $E$-region density cavity will sustain the FAC, possibly shifting away from the original center of the cavity. An initially narrow FAC associated cavity, as simulated by Doe et al. (1995); Karlsson and Marklund (1998), may evolve into a larger trough shape by such a gradual shift in position on the much longer time scales involved in main trough formation, as compared to the modeled cavity formation.

As an example of the possible loss rate due to a FAC, a current density of $1 \mu \mathrm{Am}^{-2}$ corresponds to a flow of $6 \times 10^{12}$ electrons $\mathrm{s}^{-1} \mathrm{~m}^{-2}$. Integrating the EISCAT measurements for 25 October 1988 over the observable range yields a total electron content $N_{\text {tot }}$ in the range $10^{16}-10^{18}$ electrons $\mathrm{m}^{-2}$, yielding a lifetime due to FAC loss of $10^{3}$ to $10^{5} \mathrm{~s}$. A lifetime of $10^{3} \mathrm{~s}$ is short enough to represent a significant loss mechanism.

A field-aligned current loss can be introduced in the calculations described in the previous section, starting at the latitude $\theta_{\text {shield }}$ where the electric field starts to increase (we do not expect any FAC at lower latitudes) and extending some fixed width poleward. We have tried the small width $0.5^{\circ}$, the reasonable width $1^{\circ}$ and the large width $3^{\circ}$. For all cases, most loss takes place in the stagnation trough region, because this is where field lines spend the longest time in the loss region. There must also be some current supplying energy to the load in the stagnation region, as there must be an electric field in the load frame of reference to counteract the corotation. The region poleward of the trough shows very small losses due to the relatively high drift speed and consequently, each field line spends a short time in the loss region. Therefore, a FAC-induced loss cannot be distinguished from the stagnation trough, from the general morphology of the depletion region.

Applying to the specific case discussed earlier an electron outflow loss corresponding to $1 \mu \mathrm{Am}^{-2}$ (25 October 1988), it is found that the trough depth is affected, though the total influence is much smaller than the loss due to flow stagnation and decay (see Fig. 7). The further reduction of the already low values caused by flow stagnation is, on the other hand, rather significant; in Fig. 7 it represents a further decrease of almost $75 \%$. The current used is somewhat higher than actually observed (Fig. 3). Increasing the FAC loss rate quickly gives negative densities with our simple calculation scheme (i.e. subtracting the electron outflow loss from the result shown in Fig. 5b), indicating a significant contribution. If the currents have small-scale structures of high density, they could play a role in the creation of fine-scale structure in the trough. Such structures are likely to be associated with electric field spikes as well (Karlsson and Marklund, 1998), which will also influence the ionospheric plasma.

So far we have considered only losses, but there may also be significant production, as indicated by the observations (Fig. $3 \mathrm{c}$ ). The ionization production rate $\mathrm{q}$ can be determined through the electron continuity equation

$\frac{d n}{d t}=q-\alpha n^{2}=0$,

assuming steady state and ignoring transport, $\mathrm{n}$ is the electron number density and $\alpha$ is the recombination coefficient. For the latter we use $\alpha(h)=2.5 \times 10^{-12} \exp (-\mathrm{h} / 51.2) \mathrm{m}^{3} \mathrm{~s}^{-1}$ as an altitude-dependent effective recombination coefficient 
(Vickrey et al., 1982) and $\mathrm{h}$ is altitude in $\mathrm{km}$ (valid for $\mathrm{h}>85 \mathrm{~km}$ ). Using the typical quiet-time latitude profile from 25 October 1988 shown in Fig. 3 c, we obtain a total production in the $100-180 \mathrm{~km}$ altitude region of about $10^{13} \mathrm{~m}^{-2} \mathrm{~s}^{-1}$, which can be compared with a FAC loss rate of up to $4 \times 10^{12} \mathrm{~m}^{-2} \mathrm{~s}^{-1}$ for the observed large-scale FAC depicted in Fig. 3, possibly a few times $10^{13} \mathrm{~m}^{-2} \mathrm{~s}^{-1}$ for a dense current structure. In our case the production is significantly larger than the FAC loss, except possibly in narrow filaments. Thus, the observed $E$-region production supplies all of the electrons needed to carry the current on the scale of the main ionospheric trough, though smaller-scale structures may be created by field-aligned currents. The proton precipitation may have an insufficient number flux to directly carry the R2 FAC, but, in practice, it will (when present) produce the necessary charge carriers in the $E$-region through impact ionization.

\subsection{Trough altitude profiles}

Sample altitude profiles from 7 October 1988 and 25 October 1988 are shown in Fig. 8. The latter day is somewhat more quiet and also represents lower solar activity (Table 1). These profiles are interpolated along the magnetic field direction from the scan data (see Sect. 2.1). The uncertainty estimate from the EISCAT fitting procedure has been interpolated in the same way as the density data and is indicated as horizontal bars in the figure.

The trough altitude profiles of 25 and 26 October 1988 are flatter, i.e. they do not have a pronounced $F$-region peak. The case of 7 October 1986 is somewhat different, as some scans clearly show pronounced $F$-region peaks similar to corotation and polar cap profiles, but one profile shown in Fig. 8a has a flatter profile with no pronounced $F$-region peak, just as for the 25 October 1988 case. The polar cap profiles are similar to the corotating ones, but have higher electron densities at low altitudes.

Because of the tilted beams making up a CP3 scan it is problematic to distinguish the structure in altitude and in latitude. A closer inspection reveals that structured altitude profiles as shown in some cases in Fig. 8, occur when there are significant differences between neighboring beams. On 7 October 1986 and 26 October 1988, there are cases when the trough was above the nearly field-aligned directed beam of the CP3 scan, and no sharp structures were seen. The most likely explanation for the very sharp differences is thus latitudinal structure. This is the more likely physical explanation, as strong gradients along the field line are not expected due to the high mobility of ions along the field line. Sharp latitudinal gradients, on the other hand, are rather likely.

It is worthwhile to examine if the flat trough profiles may also be an artifact due to finite latitude resolution. As seen in Fig. 8 b, the polar cap profiles (blue) have an $F$-region peak at low altitude, whereas the late time corotation profiles have a peak $F$-region peak at a much higher altitude (green profiles with lowest peak density). Combining two such profiles does indeed yield a very flat profile. To further examine this
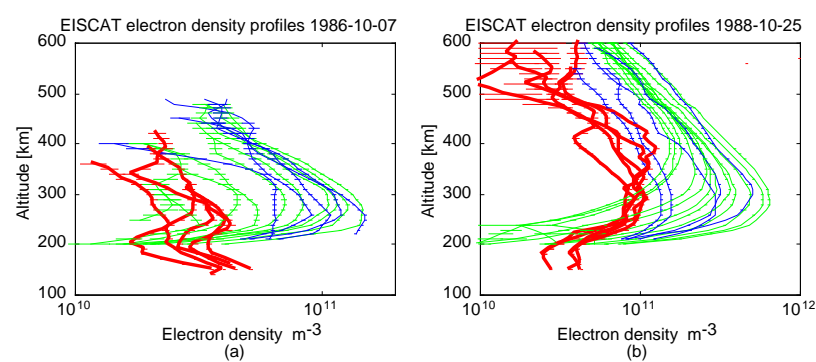

Fig. 8. Altitude density profiles $\left[\mathrm{m}^{-3}\right]$ interpolated from EISCAT CP3 scan data from 7 October 1986 (a) and 25 October 1988 (b). Green lines indicate profiles from the equatormost part of the scan. On 25 October 1988, this plasma was undisturbed and decayed in a smooth manner (panel (b)). The blue lines indicate profiles from the pole most part of the scan, a region with strong westward flow and typically rather variable densities. These are representative of plasma having convected over the polar cap. Red lines are plasma density profiles from the trough. Horizontal lines are uncertainty estimates.

we show in Fig. 9 the most closely field-aligned trough observation (black line) from 26 October 1988, together with a few other interpolated profiles from the times around this observation. As can be seen, the profile is fairly smooth and has a different altitude distribution than the corotation profiles from 25 October 1988 (green lines). It is not as flat as the interpolated profiles shown in red in the same figure or those shown in Fig. 8 b. Another profile (thick red) seems to cut through a small-scale trough minimum, seen as an indent in the middle of the profile. This indeed looks like a combination of two polar cap-like and corotation-like profiles, with the higher altitude part taken from a corotating field line, whereas the low altitude part cuts through a polar cap altitude profile. The very flat profiles seen in Fig. 8b cannot result from just one such crossing, several structures or temporal smearing must also occur. The best estimate of a trough altitude profile (the thick black line in Fig. 9) appears to have an altitude distribution somewhere in between the other types. The altitude profiles of the trough may not be as flat as indicated in Fig. 8b, but at least we can say that they differ from what we expect, due to corotation alone. Clearly it would be worthwhile to study trough altitude profiles further using field-aligned incoherent scatter radar data (e.g. the EISCAT CP1 program) but the reliable identification of the trough from such data poses a challenge.

When discussing the altitude profiles in the trough one should note that the trough plasma has a higher velocity in the ionospheric frame of reference than the corotating plasma. EISCAT observations of the ion temperature (not shown) indicate that the difference in velocity does not result in different ion temperatures for these quiet-times. Thus, the drift should not strongly affect the altitude distribution as it is mainly longitudinal (latitudinal drift may affect the altitude distribution, because of the inclination of the field line). The trough may seem rather ill-defined at the higher altitudes in the EISCAT observations. However, DMSP density data 


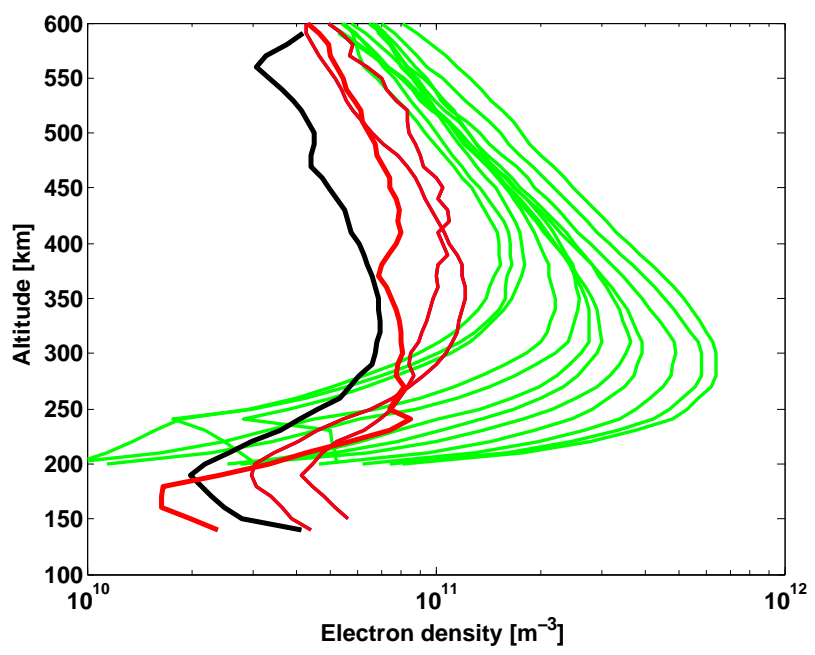

Fig. 9. Altitude density profiles $\left[\mathrm{m}^{-3}\right]$ interpolated from EISCAT CP3 scan data from 26 October 1988. Green lines indicate profiles from the equatormost part of the scan on the more quiet day 25 October 1988. The thick black line shows the altitude profile obtained when the trough was close to the field-aligned position above Troms $\varnothing$, at 17:44 UT. The red line shows some comparison trough profiles obtained in the times around the observation shown in black.

(Fig. 3a) indicate that the trough observed by EISCAT is still well defined at $840 \mathrm{~km}$, which is above the altitude of usable EISCAT measurements.

Finally, we note that it has been proposed by Kozelov and Kozelova (1995) that proton precipitation can be a direct source of plasma in the $F$-region. Essentially, precipitating protons lose charge to produce thermal ions (mainly oxygen ions). The incident proton beam loses most of its charge in the $F$-region, so that the thermal ions produced this way are of the same order of magnitude as the initial proton flux. As the proton number flux is expected to be rather small compared to typical $F$-region densities, this source of $F$-region ions should not be significant most of the time. For our case shown in Fig. 3a the proton number flux reaches $2 \times 10^{11} \mathrm{~m}^{-2} \mathrm{~s}^{-1}$, which means that it would take of the order of $10^{5} \mathrm{~s}$ to build up the lowest observed $F$-region content of $10^{16} \mathrm{~m}^{-2}$ solely from this effect. However, the effect produces a thermal ion population without any corresponding production of electrons. The additional positive charge produced at $F$-region altitudes may play a role in the redistribution of ionospheric plasma in the proton precipitation region, affecting the shape of the plasma density profile.

\section{Location of trough and proton precipitation region}

In the detailed latitude profile examined in this paper (Fig. 3) the trough and proton precipitation were closely co-located. The diffuse precipitation, as observed by EISCAT, was closely co-located with the trough throughout the evening, showing a similar latitude vs. MLT behavior to the trough (e.g. Figs. 1 and 2). The sample scan shown in Fig. 3 is thus rather representative of the relation between proton precipitation, $E$-region conductance and the trough for this quiet day. We do not present any extended results from the small statistical study we have done based on the data in Table. 1 . This is because most of the questions which can be answered from such a statistical study are much better addressed by a statistical study using low-altitude satellite data (e.g. Werner and Prölss, 1997; Karpachev, 2003) such as the DMSP satellites, which are equipped with the SSIES instrument (i.e. DMSP satellites F8 and newer). We just note that we do indeed see a $K_{p}$ dependence of the average trough location for each evening, but a large scatter of latitude of trough for each MLT bin. This is in agreement with previous studies that have found that $K_{p}$ is poor at predicting trough latitude in terms of magnetic local time for crossing the observation site (Rodger et al., 1992; Collis and Häggström, 1988), if the trough latitude vs MLT shape is variable enough to give large scatter for each MLT bin.

Finally, we note that the subauroral electric field (SAEF) events, or sub-auroral polarization streams (SAPS) reported by Karlsson et al. (1998); Foster and Vo (2002); Figueiredo et al. (2004) were well ordered by $K_{p}$, most common in the time just before midnight and were reported to occur within the trough. In contrast to our observations, the strong electric fields were anticorrelated with ionospheric conductance. A main difference between the quiet-time trough and a SAEF/SAPS may thus be whether, and to what extent protons are pitch-angle scattered in the near-Earth current sheet and precipitated. In the quiet-time trough there is a positive spatial correlation between electric field and conductance (both increase further into the trough and westward flow region; see Fig. 3 b).

\section{Conclusions}

We have made a quantitative test of the flow stagnation scenario for trough formation. The calculations include decay curves for $F$-region plasma content determined from corotating plasma on a very quiet day. It was found that flow stagnation can explain the observed plasma content between 250 and $500 \mathrm{~km}$. It is not possible from the data set used to determine whether field-aligned currents actually do contribute significantly to the depletion of the $F$-region plasma in the quiet-time evening sector ionosphere. For the lowest densities the amount of electrons needed to carry the R2 FAC is significant compared with the total number of electrons in the ionospheric footpoint of the affected field line. Indeed the ionosphere would "run out" of electrons in the simplest scenario, indicating both that the FAC may play a role in trough formation and showing the importance of ionospheric feedback, such as strong polarization electric fields. However, our estimates show that even though the proton precipitation number flux within the trough and the R2 FAC region is insufficient to directly carry the R2 FAC, it will, in practice, produce the necessary charge carriers through impact 
ionization in the ionospheric $E$-region. No downward fieldaligned current associated effect on the ionospheric plasma content would then be expected. In the studied case the ionization production due to proton precipitation was a few times higher than what was required to carry the FAC. This assumes that the FAC was evenly distributed; more narrow, intense filaments could have a more significant effect. It is suggested that this production of ionospheric charge carriers frequently plays a crucial role in the evening sector R2 FAC charge carrier budget in the dark ionosphere. In our case the ionization production, due to proton impact ionization in the trough, was about $10^{13} \mathrm{~m}^{-2} \mathrm{~s}^{-1}$ and the fieldaligned current on the scale of the trough constituted a loss of $4 \times 10^{12} \mathrm{~m}^{-2} \mathrm{~s}^{-1}$ corresponding to an observational-implied FAC of $0.7 \mu \mathrm{A} \mathrm{m}^{-2}$.

For some of the studied days the altitude profiles within the trough do not agree with just a simple stagnation and decay, i.e. the shape is different from the corotation profiles. The important difference is the much flatter altitude profiles of the trough seen in some cases. The flat altitude profiles may, to some extent, be a finite measurement resolution effect, where polar cap profiles with low altitude of the $F$ region peak are mixed with stagnation profiles with a high altitude of the $F$-region peak. This may affect attempts to distinguish between stagnation and enhanced electric field produced troughs through the shape of the electron density altitude profiles, as discussed by Crickmore et al. (1996). The sharper altitude structures sometimes observed are most likely due to latitudinal structure not properly resolved by the EISCAT scan. Denser fine-scale FAC structures are very likely to produce such fine structure in the trough plasma content, both through a direct FAC effect and through associated electric fields.

The conductance enhancement associated with the quiettime trough comes from charge exchange spread protons, yielding a spatially-smooth gradient in the right sense to support a downward field-aligned current in a region of uniform or poleward increasing westward flow. The smooth conductance gradient means that one can expect a close and simple relation between electric fields and proton precipitation, just as has been reported for the R2 FAC and proton precipitation (Fujii et al., 1990). Indeed, there is an approximate positive spatial correlation between enhanced conductance caused by proton precipitation and the net electric field (enhanced compared to the shielded lower latitudes). This is reasonable, as both are expected to be caused by the magnetospheric proton population. It is, however, a somewhat unusual voltageconductance relation.

Acknowledgements. The work of HN and TS was supported by the Swedish Research Council. DMSP data has been provided by the U. S. Air Force Research Lab., Space Vehicles Directorate, Hanscom AFB, Massachusetts, USA. We thank Fred Rich for his assistance in providing the data. EISCAT is an international association supported by Finland (SA), France (CNRS), the Federal Republic of Germany (MPG), Japan (NIPR), Norway (NFR), Sweden (VR) and the United Kingdom (PPARC).
Topical Editor M. Lester thanks R. Fujii, M. Galand and another referee for their help in evaluating this paper.

\section{References}

Banks, P. M. and Yasuhara, F.: Electric fields and conductivity in the night time E-region; A new magnetosphere-ionosphereatmosphere coupling effect, Geophys. Res. Lett., 5, 1047-1050, 1978.

Blanc, M. and Caudal, G.: The spatial distribution of magnetospheric electric fields at ionospheric altitudes: a review. 2. Theories, Ann. Geophys., 3, 27-42, 1985.

Block, L. P. and Fälthammar, C.-G.: Effects of field-aligned currents on the structure of the ionosphere, J. Geophys. Res., 73, 4807-4812, 1968.

Brinton, H. C., Grebowsky, J. M., and Brace, L. H.: The highlatitude winter $\mathrm{F}$ region at $300 \mathrm{~km}$ : thermal plasma observations from AE-C, J. Geophys. Res., 83, 4767-4776, 1978.

Collis, P. N. and Häggström, I.: Plasma convection and auroral precipitation processes associated with the main ionospheric trough at high latitudes, J. Atm. Terr. Phys., 50, 389-404, 1988.

Crickmore, R. I., Jenkins, B., and Bailey, G. J.: Variations in the altitude of the $\mathrm{F} 2$ peak associated with trough-formation processes, Ann. Geophys., 14, 628-636, 1996,

\section{SRef-ID: 1432-0576/ag/1996-14-628}

Davidson, G. T.: Expected spatial distribution of low energy protons precipitated in the auroral zones, J. Geophys. Res., 70, 1061-, 1965.

Doe, R. F., Vickrey, J. F., and Mendillo, M.: Electrodynamic model for the formation of auroral ionospheric cavities, J. Geophys. Res., 100, 9683-9696, 1995.

Figueiredo, S., Karlsson, T., and Marklund, G. T.: Investigation of subauroral ion drifts and related field-aligned currents and ionospheric Pedersen conductivity distribution, Ann. Geophys., 22, 923-934, 2004,

SRef-ID: 1432-0576/ag/2004-22-923.

Folkestad, K., Hagfors, T., and Westerlund, S.: EISCAT: an updated description of technical characteristics and operational capabilities, Radio Sci., 18, 867-879, 1983.

Foster, J. C. and Vo, H. B.: Average characteristics and activity dependence of the subauroral polarization stream, J. Geophys. Res., 107, doi:10.1029/2002JA009 409, 2002.

Fujii, R., Hoffman, R. A., and Sugiura, M.: Spatial relationships between region 2 field-aligned currents and electron and ion precipitation in the evening sector, J. Geophys. Res., 95, 18939 18 947, 1990.

Fukunishi, H.: Dynamic relationship between proton and electron auroral substorms, J. Geophys. Res., 80, 553-574, 1975.

Galand, M. and Richmond, A. D.: Ionospheric electrical conductances produced by auroral proton precipitation, J. Geophys Res., 106, 117-125, 2001.

Galand, M., Lummerzheim, D., Stephan, A. W., Bush, B. C., and Chakrabarti, S.: Electron and proton aurora observed sprectroscopically in the far ultraviolet, J. Geophys. Res., 107, doi:10.129/2001JA000 235, 2002.

Hardy, D. A., Gussenhoven, M. S., and Brautigam, D.: A statistical model of auroral ion precipitation, J. Geophys. Res., 94, 370392, 1989.

Hedin, A. E.: Extension of the MSIS thermosphere model into the middle and lower atmosphere, J. Geophys. Res., 96, 1159-1172, 1991. 
Hedin, M., Häggström, I., Pellinen-Wannberg, A., Andersson, L., Brändström, U., Gustavsson, B., Steen, Å., Westman, A., Wannberg, G., van Eyken, T., Aso, T., Cattell, C., Carlson, C. W., and Klumpar, D.: 3-D extent of the main ionospheric trough-a case study, Adv. Pol. Up. Atm. Res., 14, 157-162, 2000.

Jones, D. G., Walker, I. K., and Kersley, L.: Structure of the polward wall of the trough and the inclination of the geomagnetic field above the EISCAT radar, Ann. Geophys., 15, 740-746, 1997, SRef-ID: 1432-0576/ag/1997-15-740.

Karlsson, T. Marklund, G. T., Blomberg, L. G., and Mälkki, A.: Subauroral electric fields observed by the Freja satellite: A statistical study, J. Geophys. Res., 103, 4327-4341, 1998.

Karlsson, T. and Marklund, G. T.: Simulations of small-scale auroral current closure in the return current region, in Physics of Plasmas, MIT Center for Theoretical Geo/Cosmo Plasma Physics, 1998.

Karpachev, A. T.: The Dependence of the Main Ionospheric Trough Shape on Longitude, Altitude, Season, Local Time, and Solar and Magnetic Activity, Geomag. Aeronomy, 43, 239-251, 2003.

Knudsen, W. C.: Magnetospheric convection and the high-latitude $F_{2}$ ionosphere, J. Geophys. Res., 79, 1046-1055, 1974.

Kozelov, B. V.: Influence of the dipolar magnetic field on transport of proton-H atom fluxes in the atmosphere, Ann. Geophys., 11, 697-704, 1993.

Kozelov, B. V. and Kozelova, T. V.: Charge loss of proton flux as an additional source of plasma in F2 region, Adv. Space Res., 16, (1)159-(1)162, 1995.

Lyatsky, V. B. and Mal'tsev, P.: Origin of the Mid-Latitude Trough and of the Polar Void in the Ionospheric Density Distribution, Geomag. Aeronomy, 21, 127-128, 1981.

Newell, P. T., Meng, C.-I., and Lyons, K. M.: Suppression of discrete aurora by sunlight, Nature, 381, 766-767, 1996.

Opgenoorth, H. J., Bromage, B., Fontaine, D., La Hoz, C., Huuskonen, A., Kohl, H., Løvhaug, U.-P., Wannberg, G., Gustafsoon, G., Murphree, J. S., Eliasson, L., Marklund, G., Potemra, T. A., Kirkwood, S., Nielsen, E., and Wahlund, J.-E.: Coordinated observations with EISCAT and the Viking satellite: The decay of a westward travelling surge, Ann. Geophys., 7, 479-500, 1989.

Rees, M. H.: Physics and Chemistry of the Upper Atmosphere, Cambridge Univ. Press, New York, 1989.

Rich, F. J.: Users guide for the topside ionospheric plasma monitor (SSIES, SSIES-2 and SSIES-3) on spacecraft Defens Meteorological Satellite Program (DMSP), 1: Technical Desciption, Tech. rep., Air Force Phillips Laboratory, Hanscom AFB, MA, 1994.
Robinson, R. M., Vondrak, R. R., and Potemra, T. A.: Electrodynamic properties of the evening sector ionosphere within the region 2 field-aligned current sheet, J. Geophys. Res., 87, 731-741, 1982.

Rodger, A. S., Moffett, R. J., and Quegan, S.: The role of ion drift in the formation of ionisation troughs in the mid- and high-latitude ionosphere - A review, J. Atm. Terr. Phys., 54, 1-30, 1992.

Schunk, R. W. and Nagy, A. F.: Ionospheres: Physics, plasma physics, and chemistry, Cambridge University Press, 2000.

Schunk, R. W., Raitt, W. J., and Banks, P. M.: Effect of electric fields on the daytime high-latitude $E$ and $F$-regions, J. Geophys. Res., 80, 3121-3130, 1975.

Senior, C.: Solar and particle contributions to auroral heightintegrated conductivities from EISCAT data: a statistical study, Ann. Geophys., 9, 449-460, 1991.

Senior, C. and Blanc, M.: On the control of magnetospheric convection by the spatial distribution of ionospheric conductivities, J. Geophys. Res., 89, 261-284, 1984.

Senior, C., Sharber, J. R., de la Beaujardiere, O., Heelis, R. A., Evans, D. S., Winningham, J. D., Sugiura, M., and Hoegy, W. R.: E and F region study of the evening sector auroral oval: a Chatanika / Dynamics Explorer 2/NOAA 6 comparison, J. Geophys. Res., 92, 2477-2494, 1987.

Spiro, R. W., Heelis, R. A., and Hanson, W. B.: Ion convection and the formation of the mid-latitude ionization trough, J. Geophys. Res., 83, 5255-4264, 1978.

Turunen, T.: GEN System - a new experimental philosophy for EISCAT radars, J. Atm. Terr. Phys., 48, 1986.

Vickrey, J. F., Vondrak, R. R., and Matthews, S. J.: Energy deposition by precipitating particles and joule dissipation in the auroral ionosphere, J. Geophys. Res., 87, 5184-5196, 1982.

Werner, S. and Prölss, G. W.: The position of the ionospheric trough as a function of local time and magnetic activity, Adv. Space Res., 20, 1717-1722, 1997.

Yamauchi, M., Lundin, R., Eliasson, L., Ohtani, S., and Clemmons, J. H.: Relationship between large-, meso- and small-scale fieldaligned currents and their current carriers, in Polar Cap Boundary Phenomena, (Eds.) Moen, J., Egeland, A., and Lockwood, M., 173-188, Kluwer Acad., Norwell, Mass., 1998. 